\title{
Synchronous and vertically undulating swimming behaviour of Atlantic cod Gadus morhua
}

\author{
Björn Björnsson*, Páll Reynisson
}

Marine Research Institute, Skúlagata 4, 101 Reykjavík, Iceland

\begin{abstract}
Predatory fish often forage in schools, but observations of actual schooling behaviour in deep-water ecosystems are scarce. In a ranching study of wild Atlantic cod Gadus morhua L. in a fjord in east Iceland, observations of peculiar synchronous and vertically undulating schooling behaviour of the fish were recorded. These fish had been conditioned to feed at the sound of a low-frequency signal. On 23 April 1996, prior to a feeding session, several of these cod followed the feeding boat which drifted slowly $\left(0.35 \mathrm{~m} \mathrm{~s}^{-1}\right)$ into the fjord. During a 24 min observational period and $500 \mathrm{~m}$ drift of the boat, 8 to 12 cod were monitored with an echo sounder. These fish, approximately $60 \mathrm{~cm}$ long, showed a striking behaviour of synchronized swimming along vertically undulating paths. Six successive undulations were observed, each 40 to $60 \mathrm{~m}$ long, 10 to $20 \mathrm{~m}$ high and lasting for 2 to $3 \mathrm{~min}$. The mean angles during ascent and descent were between 50 and $60^{\circ}$. The vertical distances between the paths of single fish decreased as the school approached the bottom and increased as it ascended up into the water column. This undulating swimming behaviour may be a foraging strategy meant to sweep part of the water column in search for the depth where prey with a vertically clumped distribution is located. Additionally, synchronized swimming, where visual contact is maintained, may facilitate the detection and capture of pelagic prey.
\end{abstract}

KEY WORDS: Atlantic cod · Swimming behaviour · Synchronization · Schooling $\cdot$ Feeding strategies $\cdot$ Echolocation

\section{INTRODUCTION}

According to definition, a group of fish that stay together for social reasons is a shoal, and if they also swim in the same direction in a coordinated manner, the group is a school (Pitcher \& Parrish 1993). There are 2 main advantages of schooling: defence against predators and enhanced foraging success (Pitcher et al. 1982, Pitcher \& Parrish 1993). The many eyes of a school aid in finding patches of prey. Each fish closely monitors the feeding behaviour of its nearest neighbours, and thus the information of a prey patch which is found can spread as a wave through the school and may direct it towards a good feeding spot (Pitcher \& Parrish 1993). Once a school of alert and evasive prey is found, the predator may gain advantage by feeding in groups as opposed to solitarily (Major 1978).
Atlantic cod Gadus morhua L. is an example of a large predatory fish that may hunt in schools. It is considered a facultative schooler (Partridge et al. 1980), at times foraging alone or in small schools (Björnsson et al. 2010). Sometimes cod may form huge feeding schools of post-spawning and immature fish which appear to maximize search volumes while maintaining visual contact (Rose 1993, DeBlois \& Rose 1995, 1996).

Adult cod spend a large part of their time near the seabed but ascend frequently up into the pelagic zone (Pálsson \& Thorsteinsson 2003, Hobson et al. 2007). Possibly the fish are resting, digesting or foraging near the bottom but make excursions up into the water column in search of energy-rich pelagic prey (Strand \& Huse 2007). High-frequency recording of depth with data storage tags (DSTs) indicates 
that cod vary their vertical depth more frequently than earlier studies were able to show (Heffernan et al. 2004).

Foraging strategies of cod that facilitate the location of the depth of pelagic prey species may have been shaped by evolutionary processes and social learning (Pyke 1984, Brown \& Laland 2006). The genetic basis of fish behaviour has been demonstrated (Danzmann et al. 1993, Norton et al. 2011) and it has been shown that animals make decisions about how to find food, based on information produced by others (Brown \& Laland 2006).

Farmed and wild fish can be conditioned to aggregate and initiate feeding at the sound of an audio signal (Abbott 1972, Midling et al. 1987, Zion et al. 2007). During a ranching study with wild cod in an Icelandic fjord, the fish had been conditioned with a low-frequency audio signal to feed on trash fish flushed down a feeding pipe (Björnsson 1999). On a few occasions it had been noticed at the end of a feeding session that the cod moved up and down the water column in a wavelike formation. Therefore, on a day when the feeding boat drifted slowly across and out of the feeding area prior to a feeding session, an attempt was made to record this behaviour. We propose that these observations of synchronous and vertically undulating swimming behaviour may give an insight into the normal foraging strategy of wild cod.

\section{MATERIALS AND METHODS}

In Stödvarfjördur, a $7 \mathrm{~km}$ long fjord in east Iceland, the swimming behaviour of wild cod which had been conditioned to feed on trash fish was studied with a Simrad EY500 echo sounder coupled to a $38 \mathrm{kHz}$ $12.4^{\circ}$ split beam transducer. The transducer was mounted on the end of a $52 \mathrm{~mm}$ wide steel pipe attached to the port side of a small (5 gross register tonnage) boat at a depth of $1.0 \mathrm{~m}$. This boat had also been used for feeding the fish. The depths of the echoes were recorded, but due to wave action causing heaving and rolling of the boat, the echoes were also presented as distances from bottom. Special in-house software was used to view and analyse the data.

Prior to the study on 23 April 1996, the fish had been fed, usually 2 to 3 times $\mathrm{wk}^{-1}$ for about $10 \mathrm{mo}$, from July 1995. Fresh or previously frozen trash fish, mainly capelin Mallotus villosus, was flushed down a feeding pipe. The pipe was tugged behind the boat with the end maintained at a depth of $23 \mathrm{~m}$. Above the end of the pipe, an underwater video camera was connected with an onboard monitor to see the out-

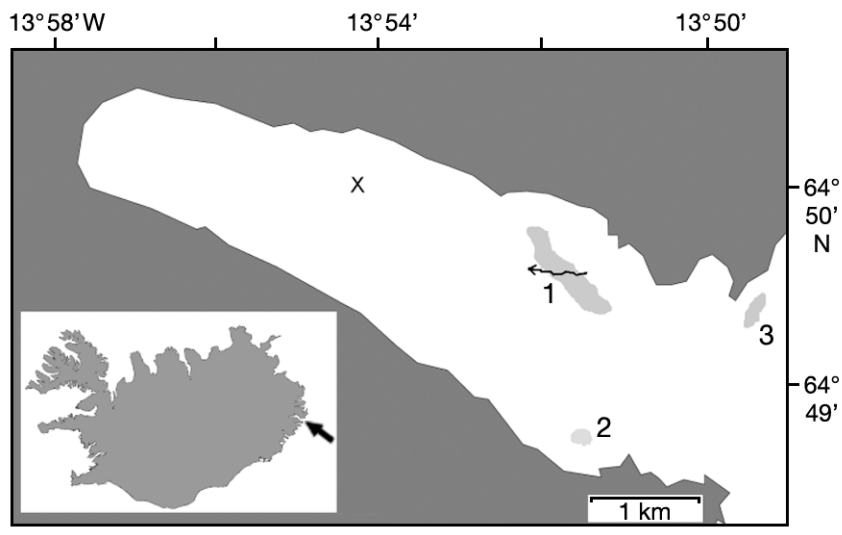

Fig. 1. Study area in Stödvarfjördur, east Iceland. Land is indicated in grey and the 3 numbered feeding areas in light grey. The arrow in Feeding Area 1 shows the drift of the boat during the observational period (13:57 to 14:21 h), and $\times$ marks the location of the temperature recording devices moored at 5 and $30 \mathrm{~m}$ depth

coming feed and the fish swimming behind. The feed was deployed in 3 distinct feeding areas near the outer part of Stödvarfjördur (Fig. 1). During feeding, a $160 \mathrm{~Hz}$ audio signal was given in short pulses with an underwater transmitter (Björnsson 1999, 2002).

At the time of the study, the fish had not been fed for $4 \mathrm{~d}$ and were thus highly motivated to feed. As the boat approached the innermost feeding area, the audio signal was activated and the boat manoeuvred slowly eastward across the feeding area. Then the propeller was uncoupled to let the boat drift for about $24 \mathrm{~min}$ and $500 \mathrm{~m}$ with an easterly moderate breeze back across and out of the feeding area, from a depth of about 30 to $45 \mathrm{~m}$. The feeding pipe was not deployed and no feed released, whereas the conditioning sound signals were constantly emitted during the drift. The computer collecting the echo sounder data was also connected to a GPS device used to estimate the location of the boat as it drifted into the fjord (Fig. 1). These measurements were used to calculate the speed of the boat.

\section{RESULTS}

Several cod followed the feeding boat as it drifted slowly $\left(0.35 \mathrm{~m} \mathrm{~s}^{-1}\right)$ into the fjord. On the echo sounder, the fish were seen to swim synchronously up and down the lower part of the water column in an undulating manner for about $15 \mathrm{~min}$ and $300 \mathrm{~m}$ distance (Fig. 2). At least 6 successive undulations were observed, each lasting for 2 to $3 \mathrm{~min}$, corresponding to a horizontal distance of 40 to $60 \mathrm{~m}$ and vertical distance of 10 to $20 \mathrm{~m}$ (Fig. 2a). The fish were able to 

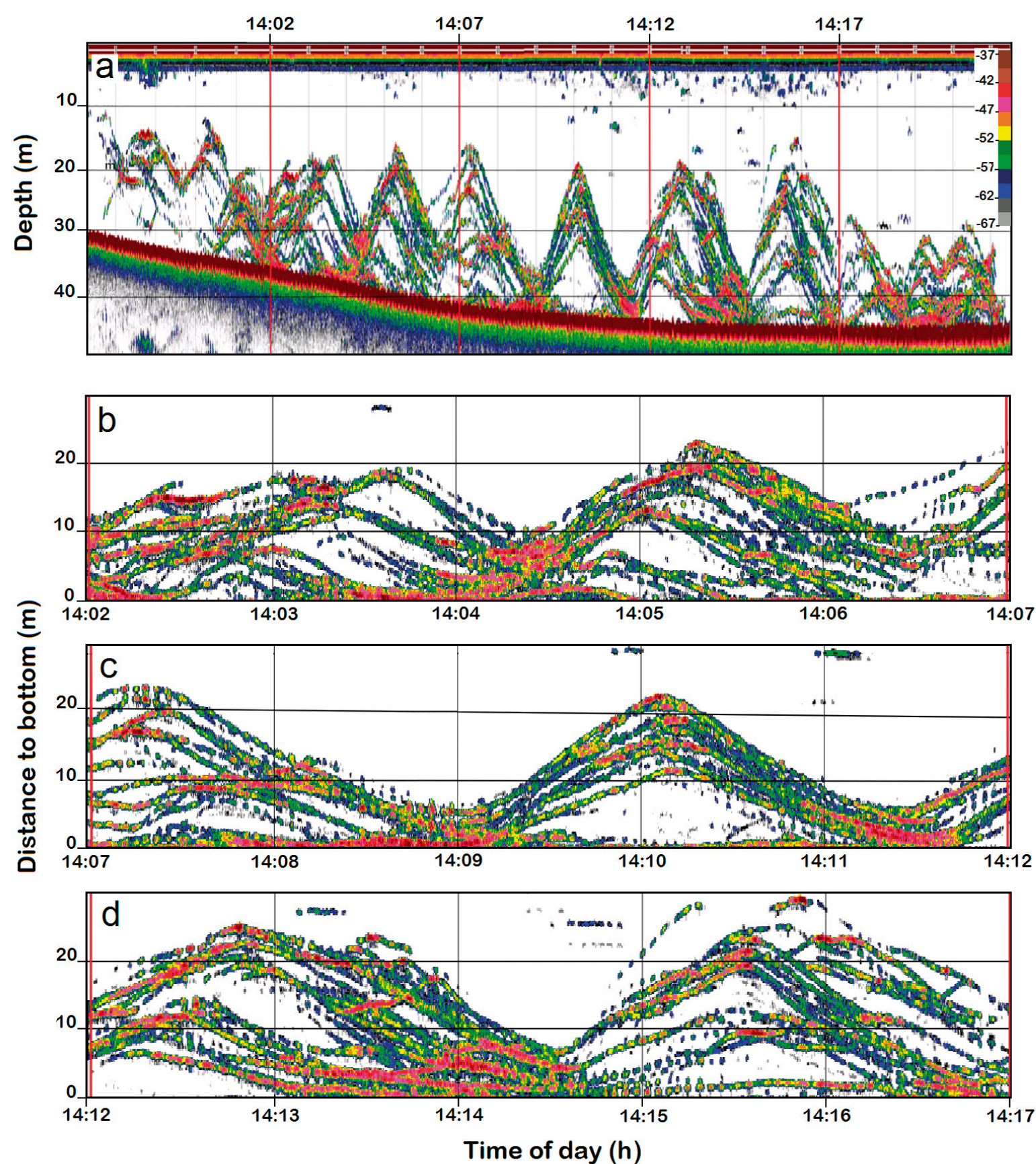

Fig. 2. Gadus morhua. Synchronized and vertically undulating swimming behaviour of several cod recorded during a slow drift of the boat $\left(0.35 \mathrm{~m} \mathrm{~s}^{-1}\right)$. The echo strength $\mathrm{S}_{\mathrm{v}} \mathrm{dB}$ ref $1 \mathrm{~m}^{-1}$ is indicated with the colour bar at the top. (a) Overview of the echoes for the time 13:57-14:21 h, and details of the 5 min intervals starting at (b) 14:02, (c) 14:07, and (d) 14:12 h. Red vertical lines in (a) mark the 3 expanded views in $(b-d)$. Note that in $(b-d)$ the echoes are presented as distances from the bottom

keep up with the boat, as tracks of individual fish could be followed for a considerable length of time (Fig. 2b-d).

The mean \pm SD angle during ascent and descent, measured for individual continuous tracks, were $53 \pm$ $14^{\circ}\left(\mathrm{n}=140\right.$, mode at 55 to $\left.60^{\circ}\right)$ and $51 \pm 15^{\circ}(\mathrm{n}=146$, mode at 60 to $\left.65^{\circ}\right)$, respectively. The tracks ranged from 5 to 68 transmissions from the echo sounder, equivalent to 0.4 to $5.4 \mathrm{~m}$ in the horizontal plane. Initially, there was some irregularity in the swimming paths, with some fish descending earlier than others, often those fish that were positioned lower in the school (Fig. 2b). The 4th undulation was the most regularly synchronized, with all fish peaking at a 
similar time (Fig. 2c). In the 5th and 6th undulations, there was again some irregularity (Fig. 2d).

Usually the fish maintained their relative vertical position within the school, and the fish in the highest position made the largest undulations. The average vertical distance between the fish increased during the ascending phase and decreased during the descending phase (Fig. 2b-d), becoming about twice as high on the peaks $(1-2 \mathrm{~m})$ as in the troughs (0.5-1.0 m). The uppermost fish were 7 to $13 \mathrm{~m}$ above bottom in the troughs and 20 to $25 \mathrm{~m}$ above bottom on the peaks (Fig. 2b-d). The signal was strongest at the top and bottom of the track where the fish must have been in a near horizontal position.

The width of the acoustic beam increased with depth from 4.3 to 6.5 and $8.6 \mathrm{~m}$ at 20,30 and $40 \mathrm{~m}$ depth, respectively. The corresponding cross sectional areas were 14.6, 33.0 and $58.6 \mathrm{~m}^{2}$. At and near the peaks, where the acoustic tracks of individual fish could be most easily distinguished, 8 to 12 fish were recorded within the beam. The volume within the acoustic beam from 20 to $35 \mathrm{~m}$ depth was about $450 \mathrm{~m}^{3}$ and thus each cod occupied on average $\sim 45 \mathrm{~m}^{3}$ of seawater.

It was assumed that cod of $\sim 60 \mathrm{~cm}$ mean length were responsible for the undulating tracks and their ground speed may thus have been $\sim 0.6$ body lengths (bl) $\mathrm{s}^{-1}$. Cod was the only species seen with the underwater camera during previous feeding sessions and the only species in 2 fish samples collected in the fjord $10 \mathrm{~d}$ prior to the study. In a sample taken with conventional hand lines in feeding areas 1 and 2, the mean $\pm \mathrm{SD}$ length of cod was $54 \pm 9 \mathrm{~cm}(\mathrm{n}=109$, range $=36-82 \mathrm{~cm}$ ). In a sample taken with gill nets (152 mm mesh size) set at known spawning grounds near the south coast, $2 \mathrm{~km}$ from the head of the fjord, the mean length was $67 \pm 7 \mathrm{~cm}(\mathrm{n}=40$, range $=$ $57-95 \mathrm{~cm})$. In a larger sample taken with a Danish seine (155 mm mesh size), a less size-selective gear, on the same spawning grounds in April of the following year, the mean length was identical $(67 \pm 8 \mathrm{~cm}, \mathrm{n}$ $=196$, range $=46-104 \mathrm{~cm})$. Observations with the underwater video camera on feeding days indicated a growing number of large and hungry fish in the schools during the first weeks of April.

The tidal currents inside the fjord were most likely slow at the time of the study, since there was only a $1.2 \mathrm{~m}$ height difference between high tide at 6:06 $\mathrm{h}$ and low tide at 12:22 h. The undulations were observed 100 to 115 min after low tide when the fjord was beginning to fill, most likely causing a slow current along the swimming path of the fish. The fish that showed the greatest undulations were swimming about $25 \%$ faster and the fish showing the smallest undulations about $10 \%$ faster than the ground speed of the boat. Assuming no currents in the study area, the swimming speeds were approximately 0.6 to $0.7 \mathrm{bl} \mathrm{s}^{-1}$, but as the fish most likely had a weak current in their back, the actual speeds through water may have been less. There was no stratification in the fjord, and the temperature was almost the same at $5 \mathrm{~m}\left(2.4^{\circ} \mathrm{C}\right)$ as at $30 \mathrm{~m}$ depth $\left(2.3^{\circ} \mathrm{C}\right)$. Visibility, as judged with the underwater camera, was good. Secchi depth was not measured in the study, but in several recent years it has been found to range between 5 and $10 \mathrm{~m}$ in Stödvarfjördur in April-May.

\section{DISCUSSION}

The free-ranging cod that were conditioned to feed on trash fish 2 to 3 times $\mathrm{wk}^{-1}$ probably remained near the seabed between feeding sessions, apparently in a more or less horizontal position. This was reasoned from observations with the echo sounder of upward moving traces of fish from the bottom every time the feeding boat approached the feeding area. On the day of the study, 23 April 1996, a cod school followed the boat as it drifted through and out of the feeding area. It recognized the conditioning sound and attempted to locate the depth of the presumed feed by swimming synchronously up and down in the water column in an undulating manner. The mean tilt angles during ascent and descent were much higher, 50 to $60^{\circ}$, than previously reported for cod, 1 to $10^{\circ}$ (McQuinn \& Winger 2003).

The question arises whether these records of undulating movements are artificial due to the anthropogenic feeding and conditioning of the fish or whether they represent the normal behavioural repertoire of wild cod. Although our study cannot answer this question, it can point out the adaptive advantage of such behaviour and refer to studies that support its existence. Furthermore, if wild cod undertake these oscillating vertical movements in nature, why have they not been reported before? The main reason may be the difficulty in measuring this phenomenon.

In most acoustic studies, the research vessel travels at a much faster speed than the fish (Rose et al. 1995) and therefore such undulating tracks of individual fish will not be picked up. If a research vessel could be manoeuvred accurately enough to follow a single target, there is the danger that the sound from the engine would disturb the natural foraging behaviour 
of the fish (Misund et al. 1992, Rosen et al. 2012). Also it is quite probable that undulating foraging behaviour of cod may only occur under certain conditions, e.g. depending on type of prey, time of year or time of day.

Cod fitted with acoustic tags have been tracked in the southern North Sea for periods up to $52 \mathrm{~h}$ from the time of release (Arnold et al. 1994), but the positioning errors with this method are too large to study high-frequency undulations such as those observed in our study. Potentially, DSTs could measure such vertically undulating behaviour, if depth was recorded with sufficient frequency (Heffernan et al. 2004). However, most published studies with DSTs have used measuring frequencies that are too low to detect high-frequency vertical changes $(2 \mathrm{~h}$ : Godø \& Michalsen $2000 ; \geq 40$ min: Pálsson \& Thorsteinsson $2003_{i} \geq 10$ min: Thorsteinsson et al. 2012). Yet, DSTs would not be suitable for detecting synchronization in swimming, as their horizontal location is usually unknown.

Cod with DSTs often perform fast vertically undulating swimming behaviour with no systematic pattern, which has been suggested to represent food searching activity (Godø \& Michalsen 2000). Estimated rates of vertical movements of cod are highly dependent on the frequency at which depth is recorded. For Barents Sea cod, the mean ascent rate was 174,90 and $41 \mathrm{~m} \mathrm{~h}^{-1}$ for recording frequency of 15, 30 and $60 \mathrm{~min}$, respectively (Heffernan et al. 2004). These results support the suggestion that vertically undulating searching behaviour is a natural foraging strategy of wild cod. Fish have been found to undertake oscillating vertical migrations in accordance with internal waves (Kaartvedt et al. 2012), but this cannot explain the undulating movements of cod in the present study, as the seawater in this relatively short, shallow and open fjord was vertically mixed at the time of the study and thus no internal waves were present.

Atlantic cod of the size in the present study (50 to $70 \mathrm{~cm}$ ) feed mainly on pelagic prey, especially capelin, euphausiids and northern shrimp Pandalus borealis (Lilly 1994, Worm \& Myers 2003, Björnsson et al. 2011, Pálsson \& Björnsson 2011). This requires 3dimensional searching. During a large-scale feeding migration of Atlantic cod along the bottom of the 350 $\mathrm{m}$ deep Newfoundland shelf, fish in 50 to $150 \mathrm{~m}$ thick schools appeared to maintain visual contact (Rose 1993). During these feeding migrations at relatively low light levels, each cod occupied on average 66 to $83 \mathrm{~m}^{3}$ of seawater (Rose 1993). In our study, conducted in shallow and clear water, the cod clearly maintained visual contact as each cod occupied only about $45 \mathrm{~m}^{3}$ of seawater in midwater and less than that near the bottom.

The adaptive advantage of vertically undulating swimming behaviour may be to facilitate the location of the depth where prey aggregate. Usually, the pelagic prey of cod form aggregations that have dimensions that are orders of magnitude larger in the horizontal than vertical plane (Ressler et al. 2005, Olafsdottir \& Rose 2012). Therefore, vertical searching may be an important strategy in locating these prey patches. For the largest cod stocks in the North Atlantic, capelin is the most important prey (Taggart et al. 1994, Dolgov 2002, Pálsson \& Björnsson 2011) and therefore cod may have evolved a foraging strategy to facilitate detection of capelin schools.

Commonly, the horizontal diameter of conglomerated migratory schools of capelin is measured in hundreds of km (Vilhjálmsson 1994, 2002, Huse et al. 2004), whereas their vertical diameter usually ranges from 50 to $150 \mathrm{~m}$ (Mowbray 2002, Davoren et al. 2006). Therefore, it may be an effective foraging strategy for cod to swim up and down in the water column to search for pelagic prey, such as capelin and euphausiids, that are spread out in a relatively thin layer. We conclude that synchronous and vertically undulating swimming may be part of the normal behavioural repertoire of wild cod.

Acknowledgements. The Fisheries Investment Fund in Iceland supported this project financially, and B. Albertsson, captain of the boat, carried out the feeding in the ranching study. Three colleagues at MRI assisted with the study: J. Jónsson built the equipment for producing underwater audio signals, B. Sigurdarson wrote the computer program to read and display the acoustic data, and J. Sólmundsson critically read the manuscript and made several useful suggestions.

\section{LITERATURE CITED}

Abbott RR (1972) Induced aggregation of pond-reared rainbow trout (Salmo gairdneri) through acoustic conditioning. Trans Am Fish Soc 101:35-43

Arnold GP, Greer Walker M, Emerson LS, Holford BH (1994) Movements of cod (Gadus morhua L.) in relation to the tidal streams in the southern North Sea. ICES J Mar Sci 51:207-232

Björnsson B (1999) Fjord-ranching of wild cod in an Icelandic fjord: effects of feeding on nutritional condition, growth rate and behaviour. In: Howell BR, Moksness E, Svåsand T (eds) Stock enhancement and sea ranching. Fishing News Books, Blackwell Science, Oxford, p 243-256

Björnsson B (2002) Effects of anthropogenic feeding on the growth rate, nutritional status and migratory behaviour of free-ranging cod in an Icelandic fjord. ICES J Mar Sci 59:1248-1255 
Björnsson B, Karlsson H, Gudbjörnsson S (2010) The presence of experienced cod (Gadus morhua) facilitates the acoustic training of naïve conspecifics. ICES CM 2010/I:09. International Council for the Exploration of the Sea, Copenhagen

Björnsson B, Reynisson P, Solmundsson J, Valdimarsson H (2011) Seasonal changes in migratory and predatory activity of two species of gadoid preying on inshore northern shrimp Pandalus borealis. J Fish Biol 78:1110-1131

Brown C, Laland K (2006) Social learning in fishes. In: Brown C, Laland $\mathrm{K}$, Krause J (eds) Fish cognition and behavior. Blackwell Publishing, Oxford, p 186-202

Danzmann RG, Ferguson MM, Noakes DLG (1993) The genetic basis of fish behaviour. In: Pitcher TJ (ed) Behaviour of teleost fishes, 2nd edn. Chapman \& Hall, London, p 3-30

> Davoren GK, Anderson JT, Montevecchi WA (2006) Shoal behaviour and maturity relations of spawning capelin (Mallotus villosus) off Newfoundland: demersal spawning and diel vertical movement patterns. Can J Fish Aquat Sci 63:268-284

> DeBlois EM, Rose GA (1995) Effect of foraging activity on the shoal structure of cod (Gadus morhua). Can J Fish Aquat Sci 52:2377-2387

> DeBlois EM, Rose GA (1996) Cross-shoal variability in the feeding habits of migrating Atlantic cod (Gadus morhua). Oecologia 108:192-196

$>$ Dolgov AV (2002) The role of capelin (Mallotus villosus) in the foodweb of the Barents Sea. ICES J Mar Sci 59: 1034-1045

> Godø OR, Michalsen K (2000) Migratory behaviour of northeast Arctic cod, studied by use of data storage tags. Fish Res 48:127-140

- Heffernan O, Righton D, Michalsen K (2004) Use of data storage tags to quantify vertical movements of cod: effects on acoustic measures. ICES J Mar Sci 61: 1062-1070

> Hobson VJ, Righton D, Metcalfe JD, Hays GC (2007) Vertical movements of North Sea cod. Mar Ecol Prog Ser 347:101-110

> Huse G, Johansen GO, Bogstad B, Gjøsæter H (2004) Studying spatial and trophic interactions between capelin and cod using individual-based modelling. ICES J Mar Sci 61:1201-1213

Kaartvedt S, Klevjer TA, Aksnes DL (2012) Internal wavemediated shading causes frequent vertical migrations in fishes. Mar Ecol Prog Ser 452:1-10

Lilly GR (1994) Predation by Atlantic cod on capelin on the southern Labrador and Northeast Newfoundland shelves during a period of changing spatial distributions. ICES Mar Sci Symp 198:600-611

Major PF (1978) Predator-prey interactions in two schooling fishes, Caranx ignobilis and Stolephorus purpureus. Anim Behav 26:760-777

McQuinn IH, Winger PD (2003) Tilt angle and target strength: target tracking of Atlantic cod (Gadus morhua) during trawling. ICES J Mar Sci 60:575-583

Midling KØ, Kristiansen TS, Ona E, Øiestad V (1987) Fjordranching with conditioned cod. ICES CM 1987/F:29. International Council for the Exploration of the Sea, Copenhagen

Misund OA, Aglen A, Beltestad AK, Dalen J (1992) Relationships between the geometric dimensions and biomass of schools. ICES J Mar Sci 49:305-315
Mowbray FK (2002) Changes in the vertical distribution of capelin (Mallotus villosus) off Newfoundland. ICES J Mar Sci 59:942-949

Norton WHJ, Stumpenhorst K, Faus-Kessler T, Folchert A and others (2011) Modulation of Fgfr1a signaling in zebrafish reveals a genetic basis for the agressionboldness syndrome. J Neurosci 31:13796-13807

Olafsdottir AH, Rose GA (2012) Influences of temperature, bathymetry and fronts on spawning migration routes of Icelandic capelin (Mallotus villosus). Fish Oceanogr 21:182-198

> Pálsson ÓK, Björnsson H (2011) Long-term changes in trophic patterns of Iceland cod and linkages to main prey stock sizes. ICES J Mar Sci 68:1488-1499

> Pálsson ÓK, Thorsteinsson V (2003) Migration patterns, ambient temperature, and growth of Icelandic cod (Gadus morhua): evidence from storage tag data. Can J Fish Aquat Sci 60:1409-1423

Partridge BL, Pitcher TJ, Cullen JM, Wilson JPF (1980) The three-dimensional structure of fish schools. Behav Ecol Sociobiol 6:277-288

Pitcher TJ, Parrish JK (1993) Functions of shoaling behaviour in teleosts. In: Pitcher TJ (ed) Behaviour of teleost fishes, 2nd edn. Chapman \& Hall, London, p 363-439

Pitcher TJ, Magurran AE, Winfield I (1982) Fish in larger shoals find food faster. Behav Ecol Sociobiol 10:149-151

> Pyke GH (1984) Optimal foraging theory: a critical review. Annu Rev Ecol Syst 15:523-575

Ressler PH, Brodeur RD, Peterson WT, Pierce SD, Vance PM, Røstad A, Barth JA (2005) The spatial distribution of euphausiid aggregations in the Northern California Current during August 2000. Deep-Sea Res II 52:89-108

$>$ Rose GA (1993) Cod spawning on a migration highway in the north-west Atlantic. Nature 366:458-461

> Rose GA, deYoung B, Colbourne EB (1995) Cod (Gadus morhua L.) migration speeds and transport relative to currents on the north-east Newfoundland Shelf. ICES J Mar Sci 52:903-913

Rosen S, Engås A, Fernö A, Jörgensen T (2012) The reactions of shoaling adult cod to a pelagic trawl: implications for commercial trawling. ICES J Mar Sci 69:303-312

Strand E, Huse G (2007) Vertical migration in adult Atlantic cod (Gadus morhua). Can J Fish Aquat Sci 64:1747-1760

Taggart CT, Anderson J, Bishop C, Colbourne E and others (1994) Overview of cod stocks, biology, and environment in the Northwest Atlantic region of Newfoundland, with emphasis on northern cod. ICES Mar Sci Symp 198: 140-157

Thorsteinsson V, Pálsson ÓK, Tómasson GG, Jónsdóttir IG, Pampoulie C (2012) Consistency in the behaviour types of the Atlantic cod: repeatability, timing of migration and geo-location. Mar Ecol Prog Ser 462:251-260

Vilhjálmsson H (1994) The Icelandic capelin stock. Capelin, Mallotus villosus (Müller) in the Iceland-Greenland-Jan Mayen area. Rit Fiskid 13:1-281

> Vilhjálmsson H (2002) Capelin (Mallotus villosus) in the Iceland-East Greenland-Jan Mayen ecosystem. ICES J Mar Sci 59:870-883

Worm B, Myers RA (2003) Meta-analysis of cod-shrimp interactions reveals top-down control in oceanic food webs. Ecology 84:162-173

Zion B, Barki A, Grinshpon J, Rosenfeld L, Karplus I (2007) Social facilitation of acoustic training in the common carp Cyprinus carpio (L.). Behaviour 144:611-630

Submitted: November 13, 2012; Accepted: June 3, 2013

Proofs received from author(s): July 4, 2013 